\title{
Cost-effectiveness of the Aerobika* oscillating positive expiratory pressure device in the management of COPD exacerbations
}

This article was published in the following Dove Press journal:

International Journal of COPD

19 October 2017

Number of times this article has been viewed

\section{Shoghag Khoudigian- \\ Sinani ${ }^{1,2}$ \\ Stacey Kowal ${ }^{3}$ \\ Jason A Suggett ${ }^{4}$ \\ Dominic P Coppolo 5}

'Faculty of Health Sciences, Department of Health Research, Methods, Evidence and Impact, McMaster University, Hamilton, ON, Canada; ${ }^{2}$ QuintilesIMS, Toronto, ON, Canada; ${ }^{3}$ QuintilesIMS, Seattle, WA, USA; ${ }^{4}$ Trudell Medical International, London, ON, Canada; ${ }^{5}$ Monaghan Medical Corporation, Syracuse, NY, USA
Correspondence: Shoghag KhoudigianSinani

QuintilesIMS TM, 6700 Century Avenue, Mississauga, ON L5N IV8, Canada Tel +l 4163166244 Email shoghag.khoudigian@quintilesims. com
Introduction: COPD places a huge clinical and economic burden on the US health care system, with acute exacerbations representing a key driver of direct medical costs. Current treatments, although effective in reducing symptoms and limiting exacerbations, do not adequately target the underlying disease processes that drive exacerbation development. The Aerobika* oscillating positive expiratory pressure (OPEP) device has been shown in a real-world effectiveness study to lower the frequency of moderate-to-severe exacerbations during a 30-day post-exacerbation period. This study sought to determine the impact on exacerbations and costs and to determine the cost-effectiveness of the Aerobika* device.

Methods: Data from published literature and national fee schedules were used to model the cost-effectiveness of the Aerobika* device in patients who had experienced an exacerbation in the previous month, or a post-exacerbation care population. Exacerbation trends and the impact of the Aerobika* device on reducing exacerbation frequency were modeled using a one-year Markov model with monthly cycles and three health states: (i) no exacerbation, (ii) exacerbation, and (iii) death. Scenario analysis and one-way sensitivity analysis (OWSA) were also performed.

Results: When the effect of Aerobika* device was assumed to last 30 days, use of the device resulted in cost-savings ( $\$ 553$ per patient) and improved outcomes (ie, six fewer exacerbations per 100 patients per year) compared to no OPEP/positive expiratory pressure therapy. When the effect of the Aerobika* device was assumed to extend beyond the conservative 30-day time frame, the Aerobika* device remained the dominant strategy ( 21 fewer exacerbations per 100 patients per year; cost savings of $\$ 1,952$ per patient). Consistency in findings after performing OWSAs indicates the robustness of results.

Conclusion: The Aerobika* device is a cost-effective treatment option that provides clinical benefit and results in direct medical cost savings in a post-exacerbation care COPD population.

Keywords: COPD, exacerbations, cost-effectiveness, Aerobika* device

\section{Introduction}

COPD is a progressive disease characterized by persistent respiratory symptoms and airflow limitation. ${ }^{1}$ Inflammatory changes in the airways, coupled with mucus buildup, limit expiratory flow and lead to lung hyperinflation, which results in the characteristic symptom of breathlessness. ${ }^{2}$ COPD patients may experience acute exacerbations, defined clinically as episodes of increasing respiratory symptoms (particularly dyspnea, cough, and sputum production, as well as increased sputum purulence) requiring treatment. ${ }^{3}$ An exacerbation of COPD causes further reduction in functional ability and impairment of quality of life. ${ }^{4}$ Patients with exacerbations of COPD symptoms frequently present to emergency rooms (ERs), and may require hospital admission. ${ }^{1}$ 
Acute care may include oxygen therapy, as well as antibiotics and oral corticosteroids. Of those patients hospitalized with COPD, approximately $20 \%$ will require rehospitalization within 30 days. ${ }^{5,6}$

Given that, in the US alone, approximately 12.7 million adults (1971-2000) have been diagnosed with COPD, and thus, the economic burden on the health care system is significant. ${ }^{1,7}$ Direct costs of COPD care were estimated to be US $\$ 30$ billion in 2010, with the cost of hospital care due to COPD exacerbations accounting for approximately half of all direct costs. ${ }^{8}$ By comparison, outpatient prescription drugs, physician costs, nursing home care, and home health care accounted for close to $20 \%, 19 \%, 12.5 \%$, and $4 \%$, respectively. In addition to direct costs, there are substantial indirect costs associated with productivity losses and costs to families. ${ }^{8}$

In an attempt to control COPD-related costs, health care policies are being introduced in a number of countries, including the US, where COPD is included in Medicare's Hospital Readmissions Reduction Program, which penalizes excess readmissions after a hospitalization for an exacerbation. ${ }^{9}$ This underlines the importance of seeking evidence-based strategies to help reduce the rate of exacerbations among COPD patients, and this is reflected in treatment guidelines. The Gold Initiative for Chronic Obstructive Lung Disease (GOLD) guidelines specifically states that steps should be taken to minimize the negative impact of exacerbations and to prevent recurrences of exacerbations (or re-exacerbations) in COPD patients. ${ }^{1}$ While there is no cure for COPD at present, symptomatic improvement can be achieved through pharmacological and non-pharmacological therapies. ${ }^{1,10}$ Bronchodilators (such as beta $_{2}$-agonists) relax bronchial smooth muscle to improve airflow and reduce symptoms of breathlessness. Inhaled corticosteroids, the mainstay of asthma therapy, are not thought to target the inflammatory changes in COPD and are only recommended for use concurrently with long-acting bronchodilators in patients with a history of exacerbations. ${ }^{1}$ The mucus buildup that also contributes to airflow limitation is not adequately addressed by commonly used agents. Thus, there is a significant unmet need to facilitate and maintain airway function in COPD patients, specifically during the post-exacerbation period when airways are most compromised. ${ }^{5,11}$

The Aerobika* device (Trudell Medical International) is a handheld, drug-free oscillating positive expiratory pressure (OPEP) device designed to help expel mucus from the lungs, expand airways, and enhance drug deposition, which has been shown to increase lung function and improve quality of life and function in patients with COPD. ${ }^{12}$ In a published real-world evidence (RWE) study, the Aerobika* device demonstrated a significant decrease in the frequency of exacerbations among COPD patients. ${ }^{13}$ The decrease in exacerbation frequency with the Aerobika* device was associated with an observed decrease in the rates of rehospitalization and ER visits. ${ }^{13}$ A reduction of hospitalization and rehospitalization events could lead to a significant impact on the major cost burden associated with COPD. ${ }^{2,14}$

While data from clinical trials remain the gold standard for measuring efficacy, an increasing emphasis is being placed on demonstrating the real-world impact of treatments. In this regard, RWE studies have gained importance in decision analysis and in shaping patient care ${ }^{15}$ As such, the study by Burudpakdee et al of the Aerobika* device is timely given its focus on effectiveness observed in the real-world setting. ${ }^{13}$ The study data also provide the opportunity to consider both the health and economic impacts of use of the Aerobika* device in COPD patients. We therefore undertook a study to model the cost-effectiveness of the Aerobika* device versus standard of care (ie, no OPEP/positive expiratory pressure [PEP] therapy) among post-exacerbation COPD patients based on RWE of effectiveness.

\section{Methods}

\section{Model structure, details, and assumptions}

A one-year Markov model using Microsoft ${ }^{\circledR}$ Excel 2010 was developed to estimate the incremental cost-effectiveness of Aerobika* device use in post-exacerbation COPD patients compared to treatment without the Aerobika* device (ie, no OPEP/PEP therapy). The post-exacerbation population was defined as patients who had recently experienced an exacerbation and were given the Aerobika* device for symptom management. ${ }^{13}$ As such, the model examines cost and health care trends for patients beginning at the time of their most recent exacerbation. This study was conducted from the US commercial payer perspective and included only direct medical costs that would be relevant to a third-party payer (ie, ER visits, hospital admissions, physician visits, and medication costs). Model inputs and structure were chosen based on published data, including real-world clinical data on the Aerobika* device, and recommendations from best practice modeling guidelines. ${ }^{13,16-18}$

The Markov model consisted of three health states: (i) no exacerbation, (ii) exacerbation, and (iii) death (Figure 1). Patients with COPD entered the model in the no-exacerbation health state, and based on different probabilities, they could experience an exacerbation, stay in the same health state, 


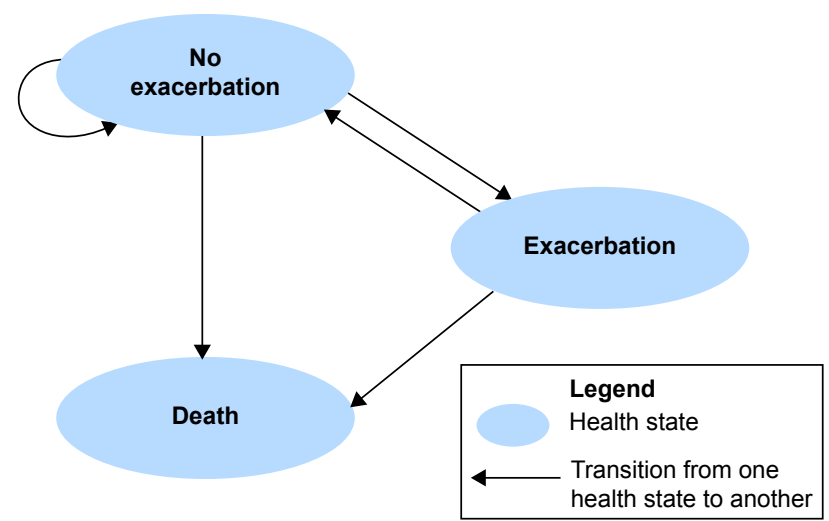

Figure I Overview of the Markov model showing the three health states: (i) no exacerbation, (ii) exacerbation, and (iii) death. Patients with COPD entered the model in the "no-exacerbation" state, and based on different probabilities, transitioned to alternative states.

or die. Death was considered a terminal state in the model. Although the model was capable of exploring outcomes over a lifetime horizon, a one-year horizon was chosen for the base case to best align with the payer perspective as well as the best practice guidelines in order to capture all health effects and costs relevant to the decision problem. ${ }^{13,17}$ The transition from one health state to another was assumed to occur monthly.

Exacerbation events in the model consisted of both severe and moderate cases. The model assumed that all patients who experienced a severe exacerbation were admitted to hospital, whereas all patients whose exacerbation was considered moderate were assumed to have an ER visit but no hospital admission. This aligns with the tracking of exacerbation events in the real-world effectiveness study, where patients who presented to the ER or who were admitted as inpatients were tracked over time. ${ }^{13}$ The model also assumed similar probability of dying irrespective of occurrence of exacerbations. This conservative assumption was chosen to allow for a focus on exacerbation events, and also considered the likelihood that incorporating increased number of deaths after exacerbation would reduce health care costs and undervalue exacerbation. Furthermore, given the short time frame for the model, the impact of mortality on final outcomes was assumed to be of minimal significance.

\section{Model parameters}

The model parameters (ie, transition probabilities, relative risks [RRs], and costs) in the economic evaluation were gathered from a variety of publicly available data sources, such as a real-world effectiveness study of the Aerobika* device ${ }^{13}$ and targeted literature searches of published studies (Tables 1 and 2). The literature searches were conducted using key biomedical databases, including MEDLINE, and search engines such as Google Scholar. Key search terms such as "COPD", "chronic obstructive pulmonary disease", "exacerbation", "hospital readmission", "cost-effectiveness", and "burden of illness" were used in these targeted search strategies.

Table I Summary of key model inputs

\begin{tabular}{|c|c|c|c|c|}
\hline \multicolumn{5}{|l|}{ Clinical and efficacy parameters } \\
\hline \multirow[t]{2}{*}{ Parameter } & \multirow[t]{2}{*}{ Base value } & \multicolumn{2}{|c|}{ Deterministic $^{\mathrm{a}}$} & \multirow{2}{*}{$\begin{array}{l}\text { Reference } \\
\text { (ie, source) }\end{array}$} \\
\hline & & Low & High & \\
\hline \multicolumn{5}{|l|}{ Monthly transition probabilities } \\
\hline Probability of experiencing exacerbation in the first month & 0.257 & 0.206 & 0.308 & 13 \\
\hline Probability of experiencing exacerbation after the first month (months $2-12)^{b}$ & 0.059 & 0.047 & $0.07 \mid$ & 19 \\
\hline Probability of dying & 0.008 & 0.006 & 0.010 & 20 \\
\hline \multicolumn{5}{|l|}{ Monthly RR for use of Aerobika* device } \\
\hline RR of exacerbation in the first month & 0.72 & 0.577 & 0.865 & Calculated values \\
\hline RR of exacerbation after the first month (months $2-12$ ) & 1.00 & 0.800 & 1.200 & using data published ${ }^{13}$ \\
\hline \multicolumn{5}{|l|}{ Unit costs of HCRU elements (cost in 2016 US dollars) } \\
\hline Aerobika* device & $\$ 100$ & $\$ 80$ & $\$ 120$ & 34 \\
\hline Emergency department visit ${ }^{c}$ & $\$ 805$ & $\$ 644$ & $\$ 966$ & 23 \\
\hline Hospital admission (diagnosis code ICD-9 496) & $\$ 8,468$ & $\$ 6,774$ & $\$ 10,161$ & 24 \\
\hline Rehospitalization (diagnosis code ICD-9 496) & $\$ 8,468$ & $\$ 6,774$ & $\$ 10,161$ & 24 \\
\hline Physician visit (CMS physician fee code 992।4) & $\$ 109$ & $\$ 87$ & $\$ 130$ & 23 \\
\hline Antibiotics prescription & $\$ 167$ & $\$ 133$ & $\$ 200$ & 25 \\
\hline Corticosteroids prescription ${ }^{e}$ & $\$ 83$ & $\$ 66$ & $\$ 100$ & 25 \\
\hline
\end{tabular}

Notes: a Deterministic values are $\pm 20 \%$ of the base value. 'PProbability of experiencing exacerbation for the remaining of the year (ie, months $2-12$ ). 'ER visit is the sum of physician fees for observation for initial, stay, and final care $(99217,99226,99220)$ and charge for using ER ward level 2 . ${ }^{\mathrm{d} A n t i b i o t i c s}$ assumed were $2 \mathrm{~g}$ Rocephin for 10 days and $500 \mathrm{mg}$ levofloxacin for 7 days; ${ }^{\mathrm{e}}$ corticosteroids assumed were Solu-Medrol for 2-3 days and prednisone for 10 days.

Abbreviations: CMS, Centers for Medicare and Medicaid Services; ER, emergency room; HCRU, health care cost and utilization; ICD-9, International Classification of Diseases, Ninth Revision; RR, relative risk. 
Table 2 Health care resource use assumptions

\begin{tabular}{llll}
\hline Parameter $^{\mathbf{a}}$ & Number of resources used per patient per month & Reference \\
\cline { 2 - 3 } & No exacerbation & Post-exacerbation & (ie, source) \\
\hline Emergency department visit & 0.001 & 0.001 & 22 \\
Hospital admission & 0 & 0 & 22 \\
Rehospitalization & 0 & 0.230 & 6,22 \\
Physician visit & 0.131 & 3.170 & 22 \\
Antibiotics prescription & 0.172 & 3.660 & 22 \\
Corticosteroids prescription & 0.113 & 2.460 & 22 \\
\hline
\end{tabular}

Note: ${ }^{a}$ Key HCRU rate's parameters were used in OWSA, where $\pm 20 \%$ of these base values were used to evaluate their impact on the outcome of the model. Abbreviations: HCRU, health care resource utilization; OWSA, one-way sensitivity analysis.

\section{Transition probabilities and treatment effect}

The probability of experiencing an exacerbation in the postexacerbation care population was derived from an RWE study of patients with a diagnosis of COPD (ie, ICD-9-CM diagnosis codes of 491.xx in any diagnosis position) in a large US claims database (Table 1) ${ }^{19}$ The probability of dying each month was derived from 2016 US Census data estimates for the general US population. ${ }^{20}$ Where necessary, monthly probabilities were calculated from annual rates given that the Markov model cycles were monthly. ${ }^{21}$

The effectiveness of the Aerobika* device in reducing the risk of exacerbation among COPD patients was based on an RWE effectiveness study. ${ }^{13}$ The total number of patients experiencing an exacerbation in the first month in two treatment cohorts (patients who used the Aerobika* device and patients who did not use the Aerobika* device) was used to estimate the $\mathrm{RR}$ of re-exacerbation with the Aerobika* device in the first month following an exacerbation ( $\mathrm{RR}=0.72 ; p<0.05$ ). We assumed these one-month data as a conservative base case and used scenario analyses to test the impact of a less conservative assumption on the effect of the Aerobika* device by applying the one-month effect on exacerbations across 12 months.

\section{Cost and resource utilization}

Health care resource utilization depends on the health states of COPD patients (Table 2) and was derived from a published RWE study by Dhamane et al. ${ }^{22}$ This study was a Medicare claims-based analysis of approximately 54,500 COPD patients (ICD-9-CM diagnosis codes of 491.xx, 492. $\mathrm{xx}$ or 496.xx) on maintenance medication, of which $44 \%$ had at least one exacerbation in a year. This study demonstrated higher rates of pharmacy claims for COPD-related medications (ie, antibiotics and corticosteroids), physician visits, and rehospitalizations during the first month after experiencing an exacerbation, in addition to the health care resources used while visiting the ER or being admitted to hospital for treatment of the exacerbation itself. ${ }^{13,22}$ The assumed direct medical costs are outlined in Table 1.
Unit costs were derived from nationally representative public sources. ${ }^{23-25}$ Specifically, the cost of an ER visit was based on the 2016 Centers for Medicare and Medicaid Services physician fee schedule and was the sum of physician fees for initial observation (code 99220; \$186.9), observation during stay (code 99217; \$73.4), and final observation (code 99226; \$106.0), as well as the cost of an ER ward charge (level 2; $\$ 439.0$ ) as reported by the Cleveland Clinic. ${ }^{23,26}$ Costs for a hospitalization due to an exacerbation were based on a query of the Agency for Healthcare Research and Quality's Healthcare Cost and Utilization Project (HCUP) database, for diagnostic code ICD-9-CM 496.xx, chronic airway obstruction. ${ }^{24}$

Medication costs associated with an exacerbation were based on dosing according to product prescribing information, with unit costs for medications obtained from Medispan Price Rx. ${ }^{25}$ Antibiotic prescriptions associated with an exacerbation assumed were $2 \mathrm{~g} /$ day Rocephin (F. Hoffmann-La Roche Ltd, Basel, Switzerland) for 10 days (\$149.40) and $500 \mathrm{mg}$ levofloxacin (Levaquin; Janssen Pharmaceuticals, Inc., Beerse, Belgium) for 7 days (\$17.30). Corticosteroid prescriptions assumed were $1-2 \mathrm{mg} / \mathrm{kg}$ Solu-Medrol (Pfizer Inc, New York City, NY, USA) q 6-12 hours for 2-3 days (\$47.46) and $2 \mathrm{mg} / \mathrm{kg}$ prednisone (Deltasone; Pfizer Inc) daily for 1-2 weeks (10 days; \$35.49).

The health care resource use (Table 2) associated with treating an exacerbation was calculated based on and accounted for the site of care. The proportion of COPD patients with moderate-to-severe exacerbations from the RWE effectiveness study ${ }^{13}$ were separated into mutually exclusive groups (ie, moderate and severe). For the Aerobika* device, $31 \%$ of observed exacerbations were moderate, while $69 \%$ were severe. In the COPD population not treated with Aerobika* device, 29\% of observed exacerbations were moderate, and the remaining $71 \%$ were severe. ${ }^{13}$ As noted previously, COPD patients with moderate exacerbations were assumed to have an ER visit, whereas COPD patients with severe exacerbations were assumed to be admitted to a hospital for appropriate treatment. ${ }^{14}$ 
This model did not include costs associated with adverse events, as no events were noted with the use of the Aerobika* device in the study published by Svenningsen et al. ${ }^{12}$ Furthermore, the model only examines exacerbation-related costs, and assumes the overall cost of COPD management is non-differential outside of the exacerbation costs modeled. All costs are reported in 2016 US dollars, and where appropriate, unit cost were inflated to 2016 US dollars using the medical care services component of the consumer price index. ${ }^{27}$

\section{Base-case analysis}

The base-case analysis was performed in COPD patients during the 30-day post-exacerbation period to estimate the reduction in re-exacerbation frequency and average cost saving per patient. The baseline risk of re-exacerbation in the post-exacerbation care population was estimated based on the observed rate of another hospital ER visit or admission within a month of the index date using a real-world sample of COPD patients hospitalized with exacerbations. ${ }^{19}$ In the base-case model, the one-month effect was assumed because data from the RWE effectiveness study were available only for this period. ${ }^{13}$ In addition, this reflects the critical 30-day period during which re-exacerbations are more common. ${ }^{5}$ The rate of exacerbations beyond 30 days was assumed non-differential when modeling the one-year time horizon.

\section{Scenario analysis}

To date, the performance of the Aerobika* device over one year has not been reported in the literature. However, additional scenarios were explored to test the model's sensitivity to alternative efficacy assumptions for the device. Specifically, the cost-effectiveness of the Aerobika* device was investigated using an alternate assumption, where the RR reduction for the first 30 days (RR: 0.72) was applied over a one-year period. This scenario analysis sought to inform the value of future research given the assumed potential impact of the device.

\section{One-way sensitivity analysis (of base case)}

To explore the uncertainty around parameters in the base-case analysis and to find the parameters with the largest impact on model outcomes, one-way sensitivity analyses (OWSAs) were conducted for all input variables. The base case value was increased and decreased by $20 \%$ for each parameter separately to estimate its impact on the cost-effectiveness. OWSA allows the user to determine the impact of change in single model input on total costs and health effects (ie, number of exacerbations). The mean value for each input $\pm 20 \%$ was considered a reasonable range to evaluate a model parameter in the deterministic model.

\section{Results}

\section{Base-case analysis}

Results of the cost-effectiveness analysis of the Aerobika* device use in the 30-day post-exacerbation care population, as compared to the population without any PEP or OPEP therapies, are summarized in Table 3. The base-case analysis led to six fewer exacerbations per 100 patients per year and an average cost saving of $\$ 553$ per patient among patients using the Aerobika* device compared to no PEP or OPEP therapy use. The use of the Aerobika* device in the post-exacerbation care population was dominant (ie, more effective and less costly). Given that the device was dominant, a formal incremental cost-effectiveness ratio (ICER) was not calculated.

\section{Scenario analysis}

The use of the Aerobika* device continued to demonstrate benefit and remained the dominant strategy when a constant average annual monthly RR of exacerbation was applied throughout the year. When applying this assumption over a one-year period, there would be 21 fewer cases of exacerbations per 100 patients per year, which results in an average cost savings of $\$ 1,952$ per patient compared to the same population without the use of PEP or OPEP therapy (Table 4).

\section{One-way sensitivity analysis}

OWSA demonstrated the impact of individual model parameters on the cost-effectiveness of the Aerobika* device. In almost all cases tested, the use of the Aerobika* device was found to be the dominant strategy compared to not using any PEP or OPEP therapy (Figure 2). The Aerobika* device's effectiveness (ie, RR of exacerbation) had the largest

Table 3 Model base-case results

\begin{tabular}{lll}
\hline Parameter & $\begin{array}{l}\text { Aerobika* } \\
\text { device }\end{array}$ & $\begin{array}{l}\text { No PEP/OPEP } \\
\text { therapy }\end{array}$ \\
\hline Total direct medical cost & $\$ 7,829$ & $\$ 8,382$ \\
Total exacerbations (average \#/patient) & 0.77 & 0.83 \\
Cost savings & $\$ 553 /$ patient \\
Number of exacerbations avoided & 0.06 (ie, six per I00 patients) \\
ICER & $\begin{array}{l}\text { Aerobika* device is the } \\
\text { dominant strategy }\end{array}$ \\
\hline
\end{tabular}

Abbreviations: ICER, incremental cost-effectiveness ratio; OPEP, oscillating positive expiratory pressure; PEP, positive expiratory pressure. 
Table 4 Scenario analysis results

\begin{tabular}{|c|c|c|}
\hline Analysis parameters & $\begin{array}{l}\text { Aerobika* } \\
\text { device }\end{array}$ & $\begin{array}{l}\text { No PEP/OPEP } \\
\text { therapy }\end{array}$ \\
\hline Total direct medical cost & $\$ 6,430$ & $\$ 8,382$ \\
\hline Total exacerbations (average \#/patient) & 0.62 & 0.83 \\
\hline Cost savings & \multicolumn{2}{|c|}{$\$ 1,952 /$ patient } \\
\hline Number of exacerbations avoided & \multicolumn{2}{|c|}{0.21 (ie, 21 per 100 patients) } \\
\hline ICER & \multicolumn{2}{|c|}{$\begin{array}{l}\text { Aerobika* device is the } \\
\text { dominant strategy }\end{array}$} \\
\hline
\end{tabular}

Abbreviations: ICER, incremental cost-effectiveness ratio; OPEP, oscillating positive expiratory pressure; PEP, positive expiratory pressure. impact on the model outcome (ie, cost-effectiveness of the Aerobika* device). Assuming a 20\% increase in benefit of the Aerobika* device during month one (RR of exacerbation reduced from 0.72 to 0.58 ), the cost saving increased to $\$ 858$ per patient and clinical benefit was estimated to be nine fewer exacerbations per 100 patients per year compared with the control cohort and the clinical benefit. When the benefit was reduced by $20 \%$ (RR of exacerbation increased to 0.86 ), cost savings were slightly lower (\$261) and there were only three

\section{A}

Parameter (low value, high value); (low output; high output)

$\begin{array}{llllll}-\$ 1,705 & -\$ 1,205 & -\$ 705 & -\$ 205 & \$ 295\end{array}$

Severe exacerbation - no Aerobika* device (56.5\%; 84.8\%)

$(\$ 444,-\$ 1,550)$

Relative risk of exacerbation after the first month $(0.800 ; 1.200)$

$(-\$ 1,546, \$ 408)$

Severe exacerbation - Aerobika* device (55.3\%; 83.0\%)

$(-\$ 1,458, \$ 351)$

Relative risk of exacerbation in the first month $(0.576 ; 0.864)$

$(-\$ 858,-\$ 261)$

Probability of experiencing exacerbation in the first month $(0.206 ; 0.308)(-\$ 448,-\$ 652)$

Moderate exacerbation - no Aerobika* device (43.5\%; $15.2 \%)$

$(-\$ 648,-\$ 458)$

B

Parameter (low value, high value); (low output; high output)

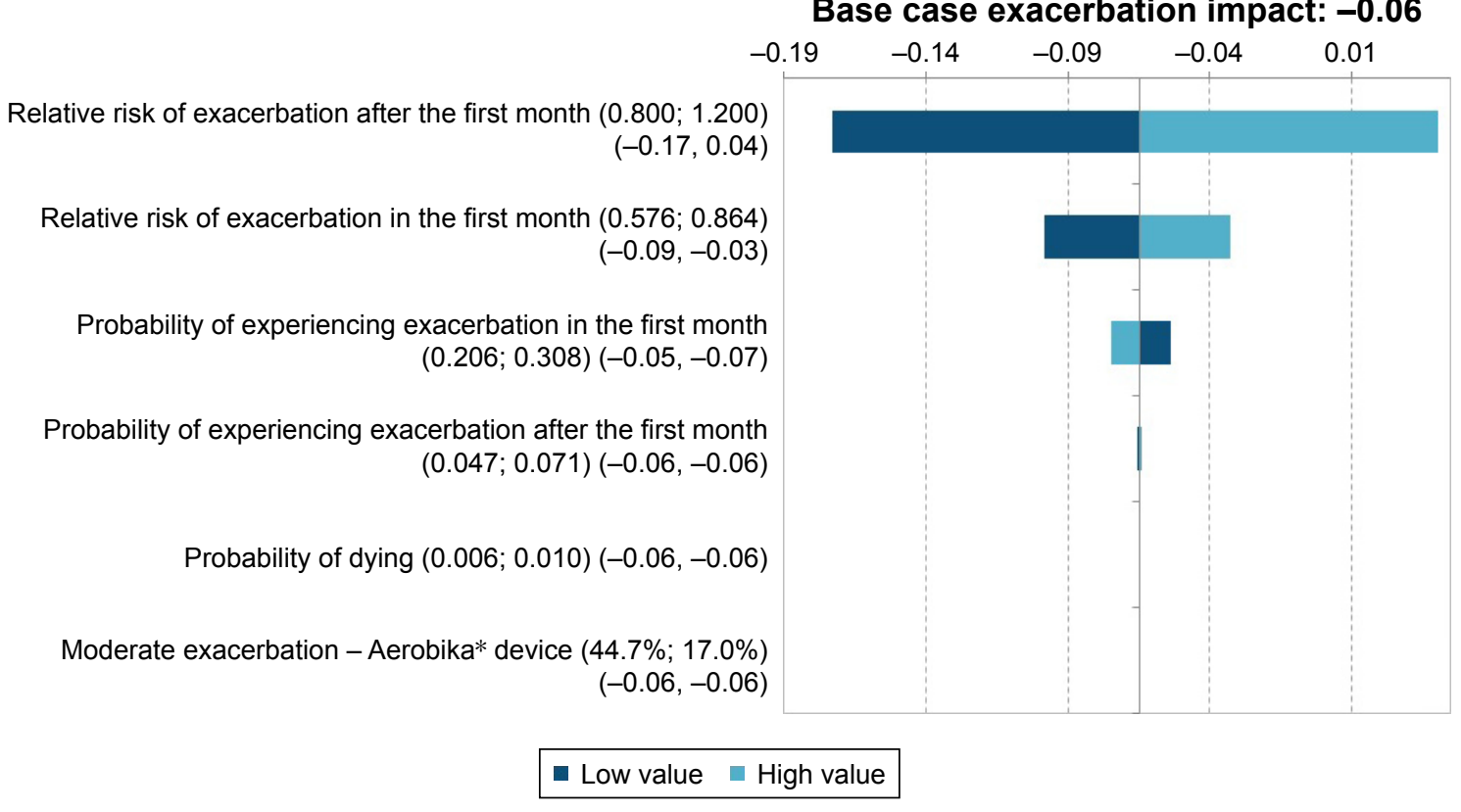

Figure 2 One-way sensitivity analysis in the post-exacerbation care population demonstrating the impact of adjusting individual model parameters on the cost-effectiveness of the Aerobika* device: (A) change in cost and (B) change in outcome. 
fewer exacerbations per 100 patients per year as compared to patients with no PEP or OPEP therapy.

Additionally, when the benefit of the Aerobika* device after the first month (months 2-12) was increased by $20 \%$ (RR exacerbations reduced to 0.8 ), cost saving increased to $\$ 1,546$ per patient and clinical benefit improved by 17 fewer exacerbations per 100 patients per year. When the RR of exacerbation with the Aerobika* device after the first month was increased by $20 \%$ (RR exacerbations increased to 1.2 ), an overall additional cost of $\$ 408$ per patient and four additional exacerbations per 100 patients per year were estimated. However, the latter scenario is unlikely given that no data suggest the use of the device would lead to increased exacerbation risk.

The other factors impacting cost-effectiveness were the proportion of severe exacerbations, probability of experiencing exacerbation in the first month and after the first month, and the provability of dying, as shown in Figure 2.

\section{Discussion}

COPD disease management via airway maintenance helps to support better lung function, and thus, improves quality of life. ${ }^{12,28}$ The Aerobika* device aids in symptom management by opening airways, mobilizing and clearing mucus buildup, and enhancing drug deposition with proprietary pressureoscillations dynamics. Further, there are no adverse events reported and no adverse event related costs due to the use of the Aerobika* device which translates into value. Leveraging RWE on effectiveness, the current study demonstrates the cost-effectiveness of the Aerobika* device as a treatment option in post-exacerbation COPD patients.

In view of the high disease burden and costs of COPD (and associated exacerbations), and the increasing pressure to improve care and reduce hospital readmissions, ${ }^{5}$ the published RWE effectiveness study ${ }^{13}$ provides timely and useful insights into the benefits of integrating the Aerobika* device into standard clinical practice, demonstrating significantly reduced exacerbations in the critical 30 days following an exacerbation event. Using these data to provide real-world inputs, the current study suggests that the device will provide cost-effective treatment for post-exacerbation COPD patients, reducing direct exacerbation-related costs. In this Markov model, results remained robust across variations in all model parameters using an OWSA, showing the Aerobika* device to be the dominant strategy. Previously published data showing statistically significant improvements with the Aerobika* device in objective clinical outcomes (such as lung function and ventilation), as well as patient-reported outcomes (including increased mucus clearance, quality of life, and exercise capacity) further reinforce our findings. ${ }^{12}$

Although the real-world effectiveness data provided direct evidence of benefit over the 30-day post-exacerbation period, there may be a reasonable assumption that some form of protection against exacerbations would continue past the first month; however, the extent of this protection requires further investigation. Within the model framework, we were able to use scenario analysis to demonstrate the potential value of the Aerobika* device when its effect is assumed to continue over a full year. In this exploratory value of information scenario analysis, the model predicts that use of the Aerobika* device would lead to further significant cost savings per patient per year, likely supporting costeffectiveness in long-term use. Given the high economic burden of COPD among the US population, especially costs relating to exacerbations, even a small benefit would make a significant impact on the economic burden on the health care system. ${ }^{8}$ Further additional studies are required to validate the real-world long-term effectiveness in reducing exacerbations to build on the findings of this study, which establishes one-year cost-effectiveness of the Aerobika* device. Furthermore, given the favorable results seen in this analysis, the use of the Aerobika* device for other conditions in which exacerbations are a key feature (including cystic fibrosis, bronchiectasis and mycobacterial infections) would be worth exploring. ${ }^{29-32}$

It is important to note that the cost savings presented in the published real-world effectiveness study of the Aerobika* device ${ }^{13}$ were greater when compared to the savings observed in this economic evaluation. Specifically, Burudpakdee et al reported estimated savings in 30-day health care costs of $\$ 3,090$ per patient in the Aerobika* device cohort, while the one-year cost savings in this cost-effectiveness model were more modest (\$553 estimated savings per patient). This observation may be explained to a large extent by differences in the cost perspective; this current cost-effectiveness analysis represented costs from the payer viewpoint, whereas the realworld claims database study took the provider cost perspective. A further explanation may be differences in the target population for examining cost trends. Specifically, the costs presented in the RWE effectiveness study ${ }^{13}$ were based only on COPD patients with subsequent exacerbations who would have had an ER visit or had been readmitted to hospital, as only those patients would show up in the inpatient/ER claims database during the study period. On the other hand, this economic analysis focuses on exacerbation-related costs for 
the average post-exacerbation COPD patient needing device reimbursement from a payer (ie, any Aerobika* device user), irrespective of whether they had another exacerbation within a specific time frame.

This cost-effectiveness study is subject to the limitations inherent with any modeling study. ${ }^{17,18}$ First, there are few published studies on the economic evaluation of PEP/ OPEP devices in COPD management, limiting the ability to benchmark inputs and findings against other published studies. Second, there is only one available published study of the Aerobika* device reporting impact on exacerbations. ${ }^{13}$ To ensure external validity and robustness of conclusions, therefore, the authors sought to identify representative sources for baseline disease burden and exacerbation risk, ${ }^{8,19}$ and conducted extensive OWSA and scenario analyses to pressure test both the assumptions used, and the influence of the model inputs. Further, values for individual model inputs ranging from the cost of a COPD exacerbation to baseline exacerbation rates were compared with other published studies to ensure trends were reasonable. ${ }^{33}$ As with any costeffectiveness analysis, the findings of this study may not be representative of other COPD populations, such as those not presenting to hospital for exacerbations. Finally, the scenario analyses sought to understand the potential impact of the Aerobika* device over a longer time period, based on assumptions extrapolated from 30-day data. The conclusions presented for these scenarios should therefore be interpreted as potential trends to be validated through future research.

Despite these limitations, there are several important conclusions of this research worth noting. This study represents the first cost-effectiveness analysis conducted for the Aerobika* device within a population of COPD patients post-exacerbation using real-world effectiveness data for the Aerobika* device, as well as robust published studies on baseline disease burden and exacerbation risk as inputs. Since the major treatment goal for COPD patients as stated in the GOLD guidelines is to minimize the negative impact of exacerbations and prevent recurrences, ${ }^{1}$ the Aerobika* device should be viewed as a valuable component of a robust treatment strategy to improve symptom control and mitigate the risk of re-exacerbations in patients with COPD.

\section{Conclusion}

This study provides evidence for the cost-effectiveness of the Aerobika* device in the management of COPD, in terms of savings in direct medical costs associated with reduction in COPD exacerbations. By using real-world clinical evidence to evaluate the incremental performance of the Aerobika* device in a cost-effectiveness framework, the device-related reduction in exacerbations was translated into payer-relevant metrics of total cost impact and total number of exacerbations in the treatment-eligible population. The consistency in findings across base case and scenario analyses suggests that model results are robust across variations in model assumptions. The insights generated from this study should be useful in informing decisions for health care providers who are seeking to develop evidence-based strategies to help reduce the rate of exacerbations (and associated costs) among COPD patients, especially in the important 30-day post-exacerbation period. This study shows that more realworld effectiveness studies are needed to demonstrate the value of new health care interventions.

\section{Acknowledgment}

This study was sponsored by Trudell Medical International.

\section{Disclosure}

SKS and SK are employees of QuintilesIMS which received funding from Trudell Medical International, London, ON, for conducting this study and for the development of this paper. The authors report no other conflicts of interest in this work.

\section{References}

1. Vogelmeier CF, Criner GJ, Martinez FJ, et al. Global Strategy for the Diagnosis, Management and Prevention of Chronic Obstructive Lung Disease 2017 Report: GOLD Executive Summary. Respirology. 2017; 22(3):575-601.

2. O'Donnell DE, Laveneziana P. Physiology and consequences of lung hyperinflation in COPD. Eur Respir Rev. 2006;15(100):61-67.

3. Wedzicha JA, Miravitlles M, Hurst JR, et al. Management of COPD exacerbations: a European Respiratory Society/American Thoracic Society guideline. Eur Respir Rev. 2017;49(3):1600791.

4. American Lung Association. COPD fact sheet [updated 2013]. Available from: http://www.lung.org/lung-health-and-diseases/lung-diseaselookup/copd/learn-about-copd/how-serious-is-copd.html. Accessed August 16, 2016.

5. Shah T, Press VG, Huisingh-Scheetz M, White SR. COPD readmissions: addressing COPD in the era of value-based health care. Chest. 2016; 150(4):916-926.

6. Jencks SF, Williams MV, Coleman EA. Rehospitalizations among patients in the Medicare fee-for-service program. N Engl J Med. 2009; 360(14):1418-1428.

7. Zamzam MA, Azab NY, El Wahsh EI, Ragab AZ, Allam EM. Quality of life in COPD patients. Egypt J Chest Dis Tuberc. 2012;61(44):281-289.

8. Guarascio AJ, Ray SM, Finch CK, Self TH. The clinical and economic burden of chronic obstructive pulmonary disease in the USA. Clinicoecon Outcomes Res. 2013;5:235-245.

9. Centers for Medicare and Medicaid Services (CMS). Readmissions reduction program. Available from: http://www.cms.gov/Medicare/ Medicare-Fee-for-Service-Payment/AcuteInpatientPPS/ReadmissionsReduction-Program.html. Accessed April 12, 2017.

10. Myers TR. Positive expiratory pressure and oscillatory positive expiratory pressure therapies. Respir Care. 2007;52(10):1308-1327. 
11. Kim JK, Lee SH, Lee BH, et al. Factors associated with exacerbation in mild-to-moderate COPD. Int J Chron Obstruct Pulmon Dis. 2016;11(1): 1327-1333.

12. Svenningsen S, Paulin GA, Sheikh K, et al. Oscillatory positive expiratory pressure in chronic obstructive pulmonary disease. COPD. 2016;13(1):66-74.

13. Burudpakdee C, Seetasith A, Dunne P, et al. A real world study of 30 day exacerbation outcomes in chronic obstructive pulmonary disease (COPD) patients managed with Aerobika OPEP. Pulm Ther. 2017; 3(1):163-171.

14. Tiep B, Carlin B, Trina Limberg RR, McCoy R. COPD patient 30-day hospital readmission reduction program. 2015. Available from: http:// onyxvantage.com/Documents/10329-001-01\%20COPD\%20Readmission\%20Reduction\%20Program\%20White\%20Paper.pdf. Accessed September 16, 2016.

15. Nguyen TN, Trocio J, Kowal S, Ferrufino CP, Munakata J, South D. Leveraging real-world evidence in disease-management decisionmaking with a total cost of care estimator. Am Health Drug Benefits. 2016;9(9):475-485.

16. ISPOR. ISPOR good outcomes research practices in economic evaluation and modeling methods. 2017. Available from: http://www.ispor. org/workpaper/practices_index.asp. Accessed August 7, 2017.

17. Caro JJ, Briggs AH, Siebert U, Kuntz KM; ISPOR-SMDM Modeling Good Research Practices Task Force. Modeling good research practices overview: a report of the ISPOR-SMDM modeling good research practices task force-1. Value Health. 2012;15(6):796-803.

18. Weinstein MC, O’Brien B, Hornberger J, et al; ISPOR Task Force on Good Research Practices - Modeling Studies. Principles of good practice for decision analytic modeling in health-care evaluation: report of the ISPOR Task Force on Good Research Practices - Modeling Studies. Value Health. 2003;6(1):9-17.

19. Pasquale MK, Sun SX, Song F, Hartnett HJ, Stemkowski SA. Impact of exacerbations on health care cost and resource utilization in chronic obstructive pulmonary disease patients with chronic bronchitis from a predominantly Medicare population. Int J Chron Obstruct Pulmon Dis. 2012;7(21):757-764

20. United States Census Bureau 2016. International data base. Available from: https:/www.census.gov/population/international/data/idb/region. php?N=\%20Results $\% 20 \& \mathrm{~T}=13 \& \mathrm{~A}=$ separate $\& \mathrm{RT}=0 \& \mathrm{Y}=2016 \& \mathrm{R}=-1-$ $\& \mathrm{C}=\mathrm{US}$. Accessed September 16, 2016.

21. Miller DK, Homan SM. Determining transition probabilities: confusion and suggestions. Med Decis Making. 1994;14(1):52-58.
22. Dhamane AD, Moretz C, Zhou Y, et al. COPD exacerbation frequency and its association with health care resource utilization and costs. Int $J$ Chron Obstruct Pulmon Dis. 2015;10:2609-2618.

23. Centers for Medicare and Medicaid Services (CMS). 2016 physician fee schedule. Available from: https:/www.cms.gov/apps/physicianfee-schedule/search/search-criteria.aspx. Accessed August 7, 2017.

24. Healthcare Cost and Utilization Project (HCUP). Rockville, MD: Agency for Healthcare Research and Quality. Available from: http:// hcupnet.ahrq.gov/. Accessed August 7, 2017.

25. Medispan Price Rx. Available from: http://pricerx.medispan.com/ Accessed August 7, 2017.

26. Cleveland Clinic. Patient price information list. 2016. Available from: http://my.clevelandclinic.org/ccf/media/files/Patients/cleveland-clinicmain-charges.pdf. Accessed December 7, 2016.

27. Bureau of Labour Statistics. Databases, tables \& calculators by subject: CPI inflation calculator. 2017. Available from: https://www.bls.gov/ ooh/. Accessed August 7, 2017.

28. Celli BR, MacNee W; ATS/ERS Task Force. Standards for the diagnosis and treatment of patients with COPD: a summary of the ATS/ ERS position paper. Eur Respir J. 2004;23(6):932-946.

29. Sanders DB, Bittner RC, Rosenfeld M, Hoffman LR, Redding GJ, Goss $\mathrm{CH}$. Failure to recover to baseline pulmonary function after cystic fibrosis pulmonary exacerbation. Am J Respir Crit Care Med. 2010; 182(5):627-632.

30. Flume PA, Mogayzel PJ Jr, Robinson KA, et al; Clinical Practice Guidelines for Pulmonary Therapies Committee. Cystic fibrosis pulmonary guidelines: treatment of pulmonary exacerbations. Am J Respir Crit Care Med. 2009;180(9):802-808.

31. Patel IS, Vlahos I, Wilkinson TM, et al. Bronchiectasis, exacerbation indices, and inflammation in chronic obstructive pulmonary disease. Am J Respir Crit Care Med. 2004;170(4):400-407.

32. Chan CH, Ho AK, Chan RC, Cheung H, Cheng AF. Mycobacteria as a cause of infective exacerbation in bronchiectasis. Postgrad Med J. 1992;68(805):896-899.

33. Wier LM, Elixhauser A, Pfunter A, Au DH. Overview of hospitalizations among patients with COPD, 2008. Healthcare Cost and Utilization Project (HCUP) Statistical Briefs [Internet]. 2011.

34. Tri-anim: Advancing Healthcare, Together. Aerobika OPEP Device, High-Flow, Low-Flow, 5 settings. Monaghan Medical Corp. 2015. Accessed August 7, 2017.
International Journal of COPD

\section{Publish your work in this journal}

The International Journal of COPD is an international, peer-reviewed journal of therapeutics and pharmacology focusing on concise rapid reporting of clinical studies and reviews in COPD. Special focus is given to the pathophysiological processes underlying the disease, intervention programs, patient focused education, and self management protocols.

\section{Dovepress}

This journal is indexed on PubMed Central, MedLine and CAS. The manuscript management system is completely online and includes a very quick and fair peer-review system, which is all easy to use. Visit http://www.dovepress.com/testimonials.php to read real quotes from published authors. 